\title{
POTENCIAL ENZIMÁTICO DE FUNGOS ENDOFÍTICOS ISOLADOS DE FOLHAS DE DIPTERYX ALATA.
}

Joyce Rodrigues de Jesus ${ }^{1}$, Jéssica Caroline Santos de Moura ${ }^{1}$, Odanir Garcia Guerra', Matheus Henrique Reis da Silva', Alex Martins Machado ${ }^{1}$.

${ }^{1}$ Universidade Federal De Mato Grosso Do Sul - UFMS, Licenciatura em Ciências Biológicas, Três Lagoas, MS. Email: Joycerodrigues3l@gmail.com

\section{RESUMO}

Fungos endofíticos habitam o interior de plantas, e devido ao seu enorme potencial de exploração, são considerados importantes recursos para obtenção de novas enzimas de aplicabilidade biotecnológica. $\mathrm{O}$ cerrado brasileiro é um bioma altamente rico, onde destaca-se o Baru (Dipteryx alata), árvore importante para o bioma e que ainda não possui sua microbiota endofítica caracterizada. O objetivo desse trabalho foi isolar fungos endofíticos da folha de baru, bem como avaliar o potencial biotecnológico desses fungos em relação à produção enzimática. Foi realizada uma avaliação qualitativa, através do índice enzimático (IE). O resultado positivo para amilase IE $\geq$ 2,0 e para lipase apenas um isolado apresentou a formação do halo translúcido. Apesar de haver necessidade de aprofundamento dos estudos em relação à caracterização desses isolados e das enzimas produzidas, os resultados positivos do potencial enzimático demonstraram que os microrganismos selecionados são promissores na obtenção das enzimas para aplicação na indústria.

Palavras-Chave : 1) Amilases 2) Potencial Biotecnológico 3) Índice Enzimático 4) Baru 5) Lipases

ENZYMATIC POTENTIAL OF ENOPHYTIC FUNGI ISOLATED FROM DIPTERYX ALATA LEAVES.

\begin{abstract}
Endophytic fungi inhabit the interior of plants, and due to their enormous exploitation potential, are considered one of the most important resources to obtain new enzymes of biotechnological applicability. The Brazilian cerrado is a highly rich biome, among the plant specimens, it is possible to stand out the "Baru" (Dipteryx alata), an important tree for the biome and it does not yet possess its characterized endophytic microbiota. The objective was to isolate endophytic fungi from "Baru", as well as to evaluate the biotechnological potential of these fungi in relation to the enzymatic production. A qualitative evaluation was performed through the enzymatic index (EI). The positive result for El amylase $\geq 2.0$ and for lipase only one isolate showed the formation of the translucent halo. Despite the need to deepen the studies in relation to characterization of these isolates and the enzymes produced, the positive results of the enzymatic potential demonstrated that the selected microorganisms are promising in obtaining the enzymes for industry application.
\end{abstract} Keywords: 1) Amylase 2) Biothecnology potential 3) Enzymatic index 4) Baru 5) Lipase 


\section{INTRODUÇÃO}

O baru (Dipteryx alata) é encontrado em toda a área contínua do domínio cerrado brasileiro e, com mais frequência, nos cerradões e matas secas. Sua distribuição é esparsa nos estados de Tocantins, Goiás e Mato Grosso do Sul, enquanto no Mato Grosso, concentra-se ao sul e leste do estado (RATTER et al., 2000). Assim como muitas outras árvores de importância econômica, o baru não possui sua microbiota endofítica caracterizada, nem relatos na literatura sobre isolamento e bioprospecção de seus fungos. Microrganismos endófiticos, são aqueles que habitam o interior de plantas, sem causar danos aos seus hospedeiros (PEIXOTO NETO; AZEVEDO; ARAÚJO et al.2002), ainda são pouco explorados apesar de constituírem uma fonte praticamente inesgotável de produtos naturais bioativos (GUNATILAK, 2006; STANIEK; WOERDENBAG; KAYSER, 2008; KOUSARI; SPITELLER, 2010). Pesquisas voltadas ao estudo da microbiota endofítica também permitem a descoberta de gêneros e espécies ainda não descritas, que podem ser potenciais produtores de enzimas de interesse biotecnológico (GUNATILAKA, 2006).

Atualmente enzimas de origem microbiana apresentam um grande potencial de aplicação biotecnológica e industrial já que podem ser produzidas em larga escala. Além de aplicabilidade industrial, enzimas sintetizadas por fungos endofíticos desempenham uma importante função ecológica ao catalisarem reações químicas e a degradação de importantes macromoléculas (CUZZI et al., 2011; ORLANDELLI et al., 2012).

Recentemente a demanda por enzimas de origem fúngica vem crescendo, e neste sentido, faz-se necessário estudos que busquem microrganismos capazes de produzirem estas enzimas, sendo o estudo em fungos endófiticos uma possibilidade de conhecimento de novas espécies produtoras destas enzimas. Alguns destes fungos conseguem secretar determinadas enzimas diretamente no meio em que se encontram, não carecendo de ruptura celular para sua liberação e facilitando sua produção em larga escala (POLIZELI et al.,2005; GUIMARÃES et al., 2006).

Dentre as enzimas produzidas por fungos, merecem destaque as enzimas amilase e lipase, devido às suas propriedades e aplicabilidades. As lipases são enzimas originárias de um grande número de bactérias, fungos, plantas e animais, tendo propriedades variáveis de acordo com sua procedência (CASTRO et al., 2004). Economicamente e industrialmente as lipases são mais utilizadas devido sua relativa facilidade de produção e a abundância de microrganismos capazes de sintetizá-las, por serem estáveis em solventes orgânicos e não necessitarem de cofatores (JAEGER; REETZ,1998). Ainda, possuem uma vasta gama de aplicações em diferentes áreas (ATTAR; AMINIFAR, 2014) como, por exemplo: detergentes (SAISUBRAMANIAN et al., 2006) medicamentos (HASAN et al., 2006), biodiesel (PARK et al., 2006) e efluentes (CASTRO et al., 2005), dentre outras.

Frente a isto, este trabalho objetivou isolar fungos endofíticos de Dipteryx alata e avaliar seu potencial biotecnológico mediante a produção de enzimas amilolíticas e lipolítica.

\section{METODOLOGIA}

\section{Isolamento dos fungos filamentosos}

As amostras de folhas de Dipterix alata foram coletadas em áreas previamente estabelecidas do município de Três Lagoas-MS, em 5 espécimes diferentes.

Cinco folhas aparentemente sadias, selecionadas de cada indivíduo, foram lavadas em água corrente para remoção de impurezas e, em seguida, colocadas sobre papel toalha para a retirada do excesso de água (SOUZA et al., 2004). Posteriormente, as folhas foram submetidas ao processo de desinfecção superficial, seguindo protocolo padronizado por Araújo e colaboradores (2002) e Schulz \& Boyle (2005).

Após o processo de desinfecção, cada folha foi cortada em fragmentos de $0,5 \mathrm{~cm}$, sendo utilizados cinco fragmentos por placa. Foram utilizados três meios de cultura diferentes: ágar batata-dextrose (BDA, Acumedia), ágar malte 2\% (MA2\%, Acumedia) e ágar sabouraud, acrescido 
de cloranfenicol $0,1 \mathrm{~g} \mathrm{~L}^{-1}$. As amostras foram plaqueadas em triplicata, e incubadas a $27^{\circ} \mathrm{C}$ por 20 dias. As placas foram observadas diariamente e quando detectado crescimento, as mesmas foram purificadas por novo crescimento, procedendo a posterior preservação pelas técnicas de Castellani e criopreservação a $-20^{\circ} \mathrm{C}$, em glicerol $20 \%$.

\section{Identificação e caracterização dos isolados}

Os isolados obtidos foram identificados por análises macroscópicas (aspectos gerais da colônia) e microscópicas (estruturas reprodutivas), sendo as estruturas observadas comparadas com as encontradas em chaves taxonômicas clássicas (ELLIS, 1976; DOMSCH; GAMS; ANDERSON, 1993; WATANABE, 2002). Culturas que não apresentaram estruturas de reprodução, foram submetidas a técnica de microcultivo para identificação das linhagens fúngicas, e ainda as que não foram identificados por este método, foram novamente cultivados em ágar aveia durante 30 dias a $27^{\circ} \mathrm{C}$, para posterior observação e identificação.

\section{Seleção da linhagem com atividade enzimática}

Dentre os fungos isolados, cepas de Aspergillus sp., Penicillum sp. e Cladosporium sp., foram utilizadas para detecção da atividade enzimática, através de testes em meio de cultura específico para o substrato enzimático (HANKIN; ANAGNOSTAKIS, 1975; SARATH et al., 1989; NEIROTII, AZEVEDO, 1988). Para isto, discos (5 mm diâmetro) de micélio de 8 linhagens destes fungos foram cultivados em BDA contendo substrato e incubados a $27^{\circ} \mathrm{C}$ por 5 dias, sendo avaliados após 7 dias, quanto a presença ou ausência de degradação. Para detecção de amilase, foi adicionado $1 \%$ de amido. Após o crescimento, foi revelado em solução de iodo $0,1 \mathrm{~N}$ e identificados como positivos através formação de um halo translúcido. Para detecção da lipase foi utilizado o substrato Tween 20 previamente esterilizado. Após o crescimento a reação positiva foi observada através da formação de cristais de sal de cálcio do ácido láurico ou formação de zonas claras em volta da colônia (HANKIN; ANAGNOSTAKIS, 1975). As cepas que apresentaram testes positivos tiveram sua atividade avaliada pelo índice enzimático (IE), dado pela relação do diâmetro médio do halo de degradação do substrato e o diâmetro médio da colônia (STAMFORD; ARAÚJO; STAMFPRD, 1998).

\section{RESULTADOS}

Foram isolados 85 fungos filamentosos da folha do Baru, sendo identificados e utilizados neste trabalho os fungos: Aspergillus sp., Penicillum sp., Cladosporium sp., e outros cinco fungos sem identificação completa de gênero.

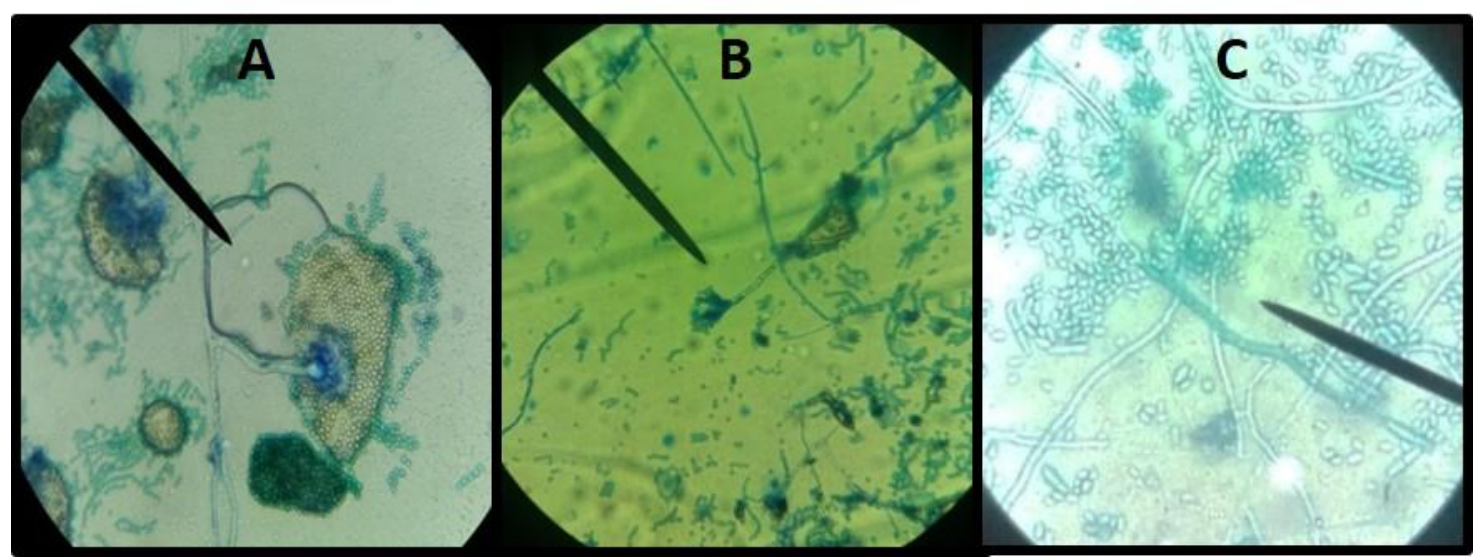

Figura 1. Fungos endofíticos detectados na folha de Baru. A. Aspergillus sp., B. Penicillum sp., C. Cladosporium sp. 
A atividade enzimática medida pelo IE mostraram índices variando de 1,27 a 2,35, sendo que segundo Lealem e colaboradores (1994) IE $\gtrsim 2,0$ são considerados com boa atividade enzimática. Para lipase, apenas um obteve a formação do halo translúcido em volta da colônia (Tabela 1).

Tabela 1. Resultado do teste de atividade enzimática por fungos isolados.

\begin{tabular}{ccccc}
\hline $\begin{array}{c}\text { Código do } \\
\text { Isolado }\end{array}$ & $\begin{array}{c}\text { Origem do } \\
\text { Isolado }\end{array}$ & Fungo isolado & \multicolumn{2}{c}{ Atividade enzimática } \\
\hline B3MP2 & Folha & Penicillium $s p$. & IE: 1,46 & Lipolítica \\
\hline B3MP1 & Folha & Penicillium $s p$. & IE: 1,42 & $(-)$ \\
B5P10 & Folha & Cladosporium $s p$. & IE: 1,38 & $(-)$ \\
B3M17 & Folha & Aspergillus $s p$. & IE: 1,27 & $(-)$ \\
B3MP19 & Folha & Aspergillus $s p$. & IE: 1,85 & $(-)$ \\
B3MP18 & Folha & Aspergillus $s p$. & IE: 2,35 & $(-)$ \\
B3MP16 & Folha & Aspergillus $s p$. & IE: 1,93 & $(-)$ \\
B5M33 & Folha & Aspergillus $s p$. & IE: 1,91 & $(+)$ \\
\hline
\end{tabular}

IE: média do índice enzimático em triplicata, (-) ausência de halo, (+) presença de halo.

Cuzzi e colaboradores (2011) realizaram analisando as produções de enzimas hidrolitícas em 11 espécies de fungos endófiticos isolados, observaram atividade positiva para a amilase em 10 isolados, sendo classificados com PZ2 (atividade positiva), variando o IE: 0,66 a 0,98. Dentro deste critério, os fungos analisados produzirem índices enzimáticos bastantes satisfatórios, IE $\geq$ que 1,0 .

\section{DISCUSSÃO}

Griffin (1994), analisando a produção de amilase em fungos filamentosos observou uma variação de acordo com o gênero e a espécie, semelhante ao observado neste trabalho, onde o gênero Aspergillus sp. mostrou os melhores IEs.

Treichel e colaboradores (2010) em trabalhos semelhantes, observaram que os gêneros Penicillium sp. e Aspergillus sp. apresentavam resultados satisfatórios quanto a produção de lipase, entretanto, apesar de encontrarmos uma cepa de Aspergillus sp. positiva para lipase, todas as outras linhagens foram negativas. Colen (2006), observa que estas diferenças de atividade podem estar relacionadas a padrões físico-químicos específicos para cada linhagem. Ainda, Colen, Junqueira e Moraes-Santos (2006) enfatizam que o substrato escolhido, pode afetar diretamente a produção e secreção de uma enzima, permitindo hipotetizar, que a não detecção de atividade de lipase possa ser devido ao substrato utilizado, sendo sugerido análises posteriores utilizando sementes de soja, fibra de dendê, entre outros.

\section{CONCLUSÃO}

Este trabalho demostrou a possibilidade da produção de amilase pelos microrganismos endófiticos presente nas folhas do baru. Porém há a necessidades de estudos mais detalhados e com outros substratos, que permitiam obter um panorama completo da produção destas enzimas por estes microrganismos.

\section{REFERÊNCIAS}

ARAUJO WL, MARCON J, MACCHERONI JR W, VAN ELSAS JD, VAN VUURDE JWL AND AZEVEDO JL (2002) Diversity of endophytic bacterial populations and their interactions with Xylella fastidiosa in 
Citrus plants. Appl Environ Microbiol 68:4906-4914. https://doi.org/10.1128/AEM.68.10.4906$\underline{4914.2002}$

ATTAR, F.; AMINIFAR, M. Spectroscopic techniques used for enzyme evaluation in food industry. International conference on nutrition and food sciences, v. 71, p. 23-27, 2014.

AZEVEDO, J.L. 1998. Microrganismos endofíticos. Pp. 117137. In: I.S. Melo \& J.L. Azevedo (eds.). Ecologia Microbiana. Jaguariúna, Embrapa-CNPMA.

CASTELLANI, A.A Maintenance And Cultivation of the common pathogenic fungi of man in strerile distilled water: further researches. Journal of Tropical Medicine \& Hygiene, Mclean,v.70, p.181184, 1967.

CASTRO, H. F.; MENDES A.A.; PEREIRA, E.B.; JÚNIOR A.F. Aplicação de lipases no tratamento de águas residuárias com elevados teores de lipídeos. Química nova, v. 28, p. 296-305, 2005. https://doi.org/10.1590/S0100-40422005000200022

CASTRO, H.F.; MENDES, A.A.; SANTOS, J.C. Modificação de óleos e gorduras por biotransformação. Química Nova, v.27, n.1, p. 146-156, 2004. https://doi.org/10.1590/S0100-40422004000100025

COLEN, G. Isolamente e Seleção de Fungos Filamentosos Produtores de Lipases. 2006. 206p. Tese (Doutorado em Ciências de alimentos). Faculdade de Farmácia, Universidade Federal de Minas Gerais, Belo Horizonte, 2006.

COLEN, G.; JUNQUEIRA, R.G.; MORAES-SANTOS, T. Isolation and screening of alkaline lipaseproducing fungi from Brazilian savanna soil. World Journal of Microbiology \& Biotechnology V. 22, p.881-885, 2006. https://doi.org/10.1007/s11274-005-9118-9

CUZZI, C. et al. Enzimas extracelulares produzidas por fungos endofíticos isolados de Baccharis Dracunculifolia D.C (Asteraeceae). Global Science and Technology, v.4 n.02, p.47-57, mai/ago 2011.

CUZZI, C.; LINK, S.; VILANI, A.; ONOFRE, S. B. Enzimas extracelulares produzidas por fungos endofíticos isolados de Baccharis dracunculifolia DC (ASTERAECEAE). Global Science and Technology, v. 4, n. 2, 2011.

DOMSCH, K.H., GAMS, W., ANDERSON, T.H. (1980). Compendium of soil fungi. Academic press, New York.

ELLIS, M.B. (1976). More dematiaceous hyphomycetes Commonwealth Mycological Institute, Kew, Surrey, U.K.

GRIFFIN, D.H. 1994. Fungal Physiology. New York, Willey-Liss.

GUIMARÃES, L. H. S. et al. Screening of filamentous fungi for production of enzymes of biotechnological interest. Brazilian Journal of Microbiology, São Paulo, v. 37, n. 4, p. 474-480, 2006. https://doi.org/10.1590/S1517-83822006000400014 
GUNATILAKA, A. A. L. Natural products from plant-associated microorganisms: distribution, structural diversity, bioactivity, and implications of their occurrence. Journal of Natural Products, India, v. 69, n. 3, p. 509-526, 2006. https://doi.org/10.1021/np058128n

HANKIN, L.; ANAGNOSTAKIS, S. L. The use of solid media for detection of enzymes production by fungi. Mycologia, New York, v. 67, n. 3, p. 597-607, Nov./Dec. 1975. https://doi.org/10.1080/00275514.1975.12019782

HASAN, F.; SHAH, A.A.; HAMEED, A. Industrial applications of microbiais lipases. Enzyme and Microbial Technology, v. 39, p. 235-25, 2006. https://doi.org/10.1016/i.enzmictec.2005.10.016

JAEGER, K.E.; REETZ, M.T. Microbiais lipases from versatile tools for biotechnology. Trends in Biotechnology, Amsterdam, v. 16, p. 396-403, 1998. https://doi.org/10.1016/S01677799(98)01195-0

LEALEM, F.; GASHE, B.A. Amylase production by a gram-positive bacterium isolated from fermenting tef. (Eraglostis tef.). Journal of Applied Bacteriology, v. 77, p. 348-352, 1994. https://doi.org/10.1111/j.1365-2672.1994.tb03084.x

Neirotii, E. \& Azevedo, I.L. 1988. Técnicas semiquantitativas de avaliação de produção de celulase em Humicola sp. Revista de Microbiologia 19: 78-81.

ORLANDELLI, R. C.; SPECIAN, V.; FELBER, A. C.; PAMPHILE, J. A. Enzimas de interesse industrial: produção por fungos e aplicações. SaBios-Revista de Saúde e Biologia, v. 7, n. 3, p.97-109, 2012.

PANDEY, A. Et al. Advances in microbial amylases. Biotechnology Applied Biochemistry, v.31, p.135-152, 2000. https://doi.org/10.1042/BA19990073

PARK, E. Y.; SATO, M.; KOJIMA, S. Fatty acid methyl ester production using lipaseimmobilizing silica particles with different particle sizes and different specific surface areas. Enzyme and Microbial Technology, v. 39, p. 889-896, 2006. https://doi.org/10.1016/i.enzmictec.2006.01.022

POLIZELI, M. L. T. M. et al. Xylanases from fungi: properties and industrial applications. Applied Microbiology and Biotechnology, Berlin, v. 67, n. 5, p. 577-591, 2005. https://doi.org/10.1007/s00253-005-1904-7

RATTER, J.A. et al. Estudo preliminar da distribuição das espécies lenhosas da fitofisionomia cerrado sentido restrito nos estados compreendidos pelo bioma Cerrado. Boletim do Herbário Esechias Paulo Heringer, v. 5. p.5-43, 2000.

SARTH, G.; DE LA MOTTE, R.S. \& WAGNER, F.W. 1989. Protease assay methods. Pp. 25-54. In: R.J. Beynon \& J.S. Bonde (eds.). Proteolytics enzymes: an pratical approach. Oxford, Oxford University Press.

SCHULZ B, BOYLE C (2005) The endophytic continuum. Mycol Res 109:661-686. https://doi.org/10.1017/S095375620500273X

SOUZA, A. Q. L.; SOUZA, A. D. L.; ASTOLFI FILHO, S.; BELÉM PINHEIRO, M. L.; SARQUIS, M. I. M.; PEREIRA, J. O. Atividade antimicrobiana de fungos endofíticos isolados de plantas tóxicas da 
amazônia: Palicourea longiflora (aubl.) rich e Strychnos cogens bentham. Acta Amazônica, Manaus, v. 34, n. 2, p. 185-195, 2004. https://doi.org/10.1590/S0044-59672004000200006

STAMFORD, T. L. M.; ARAÚJO, J. M.; STAMFORD, N. P. Enzymatic Activity of microorganisms isolated from yam bean legume (Pachyrhizus erosus L. Urban) (Pachyrhizus erosus L. Urban). Ciência e Tecnologia de Alimentos, v. 18, p. 382-385, 1998. https://doi.org/10.1590/S010120611998000400004

TREICHEL, H. Et al. A Review on Microbial Lipases Production. Food and Bioprocess Technology, v.3, p.182-196, 2010. https://doi.org/10.1007/s11947-009-0202-2

WATANABE, T. (2002). Pictorial Atlas of soil and seed fungi. Morphologies of cultured Fungi and Key to species. 2nd edition, CRC press. London. https://doi.org/10.1201/9781420040821 